\title{
Organizing Care for Complex Patients in the Patient-Centered Medical Home
}

Eugene C. Rich, $M D^{1}$

Debra Lipson, MHSA ${ }^{1}$

Jenna Libersky, $M P H^{1}$

Deborab N. Peikes, PbD

Michael L. Parchman, MD, MPH

'Mathematica Policy Research, Washington, DC

${ }^{2}$ Agency for Healthcare Research \& Quality, Rockville, Maryland
Conflicts of interest: authors report none.

\section{CORRESPONDING AUTHOR}

Eugene C. Rich, MD

Mathematica Policy Research 600 Maryland Ave SW, Ste 550 Washington, DC 20024-2512 ERich@Mathematica-Mpr.com
Ann Fam Med 2012;10:60-62. doi:10.1370/afm.1351.

$\mathrm{T}$ The patient-centered medical home (PCMH) is a model for strengthening primary care through the reorganization of existing practices to provide patient-centered, comprehensive, coordinated, and accessible care that is continuously improved through a systems-based approach to quality and safety. ${ }^{1}$ PCMH efforts have focused thus far on improved access to and coordination of medical services for all patients. There are, however, patients with more complex health care needs who require more intensive medical services coordinated across multiple clinicians, as well as a wide range of social supports to maintain health and functioning. Two groups of community-dwelling patients have especially complex health and social support needs: frail elderly and working-age adults with disabilities. Medical homes face many challenges in providing optimal care to these patients.

This report is a summary of work by the Agency for Healthcare Research \& Quality and Mathematica Policy Research on policies and strategies to help typical, smaller primary care practices transform into effective medical homes that appropriately serve patients with complex needs. It draws on the experience of 5 programs around the country that illustrate promising approaches for supporting and collaborating with smaller, independent primary care practices serving these challenging patients. All the programs allow patients with complex needs to maintain existing relationships with their primary care clinicians while giving small practices the resources to overcome barriers to providing excellent care to these patients. More details can be found in the full white paper at http:// www.pcmh.ahrq.gov. ${ }^{2}$

\section{METHODS}

Twenty promising programs were identified using searches of published and grey literature, conference presentations, and recommendations from a technical expert panel. Five programs were selected for in-depth study based on 4 criteria: (1) they serve frail elderly or adults with disabilities; (2) they work with a variety of small primary care practices, defined as fewer than 10 primary care clinicians, (3) they coordinate care across medical and social service systems; and (4) they have been operating for at least 2 years.

\section{FINDINGS}

The selected programs are sponsored by different types of organizations: regional physician-led practice support organizations, nonprofit health plans, an integrated health system, and a state health agency. Most programs work in partnership with public payers, such as state Medicaid programs and Medicare (through Medicare Advantage Special Needs Plans or Medicare demonstration programs), and with various community 
agencies. The number of participating practices in each program varies from about a dozen to more than 1,400 . The programs used a variety of approaches to support primary care practices in caring for patients with complex needs.

\section{Care Coordinators}

Providing or arranging for care coordinators to support the primary care practices is a prominent feature across the programs. The Commonwealth Care Alliance (CCA) in Massachusetts, Community Care of North Carolina (CCNC), and Community Health Partnership (CHP) of Wisconsin hire or contract with care coordination staff to work with the practices, in the practice offices or in close cooperation with them, to assess care needs, arrange for specialty and community services, and integrate care across medical and social service systems and among multiple clinicians. Summa Health System arranges for care coordination by case managers in a local area agency on aging, and Minnesota's Health Care Homes program requires the practices to designate which staff in the practice will be responsible for care coordination. There is wide variation in how care coordinators are shared with primary care practices across and within each program; average case manager caseloads range from 40 to more than 1,000 patients, depending on the complexity or severity of the patients in the practice who receive case management and the funding and resources available.

\section{Technical Assistance and Practice Support}

Most programs dedicate considerable resources to direct practice support by helping them reorganize workflow and systems and by providing tools to enhance practice capacity to assure continuous access and care coordination. Additional supports to practices include 24-7 call lines for patients, which complement or substitute for a practice's after-hours coverage; recommendations on (or provision of) electronic health record (EHR) systems, Web-based health information technology (IT) registries, and referral tracking systems; and support in tracking service utilization and quality indicators for the practice patient panel. Some also facilitate ready access to geriatrics or mental health consultation.

\section{Health IT to Identify and Monitor At-Risk Patients}

In addition to requiring that practices use EHRs, some programs require the practices to use an EHR system that feeds information to the program sponsor as a term of participation. These systems allow the program to readily access clinician- or organization-level data on cost, utilization, and outcomes, which allow program staff to identify and target care management approaches to high-need, high-cost users.

\section{Quality Improvement Activities}

All of the programs emphasize quality improvement, supported by the use of the EHR and data capabilities described above. For example, CCA collects data from the Web-based EHRs that its practices maintain, and it meets every quarter with practice leaders to review and compare the practice's results on key indicators, such as 30-day hospital admission rates, with those for all program participants. They then jointly identify opportunities for improvement.

\section{Learning Opportunities}

Team-based quality improvement through peer-topeer learning and in-person meetings is another common approach, though the breadth and intensity vary. CCNC uses a multilevel approach that provides technical assistance to regional network staff, who then sponsor peer-to-peer learning for the primary care practices within each region. Minnesota sponsors a learning collaborative in which practices meet to share strategies for implementing medical home criteria and improving care. Summa Health System also facilitates shared learning through monthly, in-person meetings during which skilled nursing facilities, palliative care specialists, geriatricians, home care agencies, care coordinators, and community agencies together identify ways to improve transitions of care.

\section{Practice Payment}

To ensure consistent and active participation of primary care clinicians in care coordination and teambased care, most programs pay the practices for the time spent on these activities. These extra payments help with practice recruitment and at least partially compensate the practice for the additional time and resources involved in providing enhanced care. Although different reimbursement mechanisms were used, the most common was some form of per-member per-month fee.

\section{NEXT STEPS}

Patients with complex health care needs represent the greatest challenge to transforming small primary care practices into high-functioning medical homes. These patients also present a great opportunity for medical homes to dramatically improve outcomes, such as lower costs, higher-quality care, and better care experiences for patients and clinicians. To achieve these aims, small practices will require enhanced support and resources-beyond those needed to meet current 
medical home standards-to deliver optimal care to patients with complex care needs. The 2 most crucial supports appear to be additional practice reimbursement for time spent coordinating care and integration of care coordinators with primary care teams.

Key questions remain. How should payment to the primary care practices be structured to compensate practices for the extra time and resources needed to provide care for patients with widely varying conditions, disabilities, and levels of severity? Are there ways to harmonize practice payment with funding for community resource organizations so as to promote team-based care for this population? What outcomes should be measured to evaluate efforts to enhance care for patients with complex care needs? Given the diversity of communities and practices across the country, further studies need to clarify which models are most effective for practices of varying sizes and patient mixes, as well as those that operate in different settings.

To read or post commentaries in response to this article, see it online at http://www.annfammed.org/content/10/1/60.
Key words: Primary health care; patient-centered care; chronic disease; frail older adults; persons with disabilities; health policy; Agency for Healthcare Research and Quality (U.S.)

Submitted November 7, 2011; submitted, revised, November 10, 2011; accepted November 11, 2011.

Funding support: This paper was supported by the Agency for Healthcare Research \& Quality contract number HHSA290200900019I TO2.

Disclaimer: The views expressed in this article are those of the authors and do not necessarily represent those of the Agency for Healthcare Research and Quality or the US Department of Health and Human Services.

\section{References}

1. Agency for Healthcare Research and Quality (AHRQ). What is the PCMH? AHRQ's definition of the medical home. 2011. http://pcmh. ahrq.gov/portal/server.pt/community/pcmh__home/1483/PCMH_ Defining\%20the\%20PCMH_v2. Accessed Nov 7, 2011.

2. Agency for Healthcare Research and Quality (AHRQ). Coordinating care for adults with complex care needs in the patientcentered medical home: challenges and solutions. 2011. http:// pcmh.ahrq.gov/portal/server.pt/community/pcmh__home/1483/ PCMH_Home_Papers\%20Briefs\%20and\%200the\%20Resources_v2.

\section{REGISTER BY MARCH 19 TH \& SAVE $\$ 75$ !}

\section{STFM 45th Annual Spring Conference}

April 25-29, 2012

Sheraton Seattle Hotel

\section{Seattle, Washington}

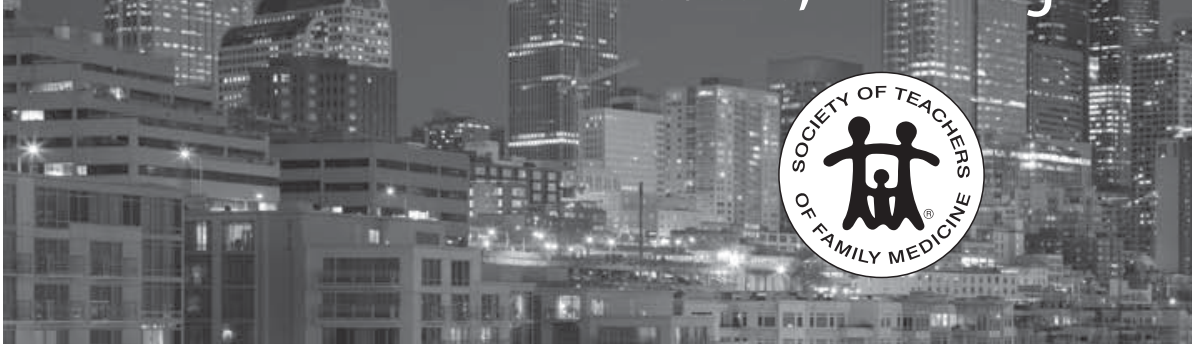

Don't miss the nation's most energized networking forum for family medicine educators. 